\title{
The Efficacy of Submucosal Tramadol in the Postoperative Treatment of Pain Following Septoplasty Operations
}

\author{
Dr K. G. Somashekar ${ }^{1}$, Dr Shazia ${ }^{2}$ \\ ${ }^{1}$ Professor and HOD, Department of ENT, Kempegowda Institute of Medical Sciences, K.R Road V.V Puram, Bangalore- 560004 \\ Karnataka India \\ ${ }^{2}$ Junior Resident, Department of ENT, Kempegowda Institute of Medical Sciences, K.R Road V.V Puram, Bangalore- 560004 Karnataka \\ India
}

\begin{abstract}
Aim: To evaluate the effect of submucosal tramadol on VAS scores after septoplasty operations and patient satisfaction. Method: 100 patients between 18 and 60 years of age who were scheduled for elective septoplasty were enrolled in a double-blind randomized controlled study. The patients were randomly divided into 2 group, group $T$ and Group P. In Group T, at the end of surgery following hemostasis, $2 \mathrm{mg} / \mathrm{kg}$ tramadol was applied as submucosal infiltration to both surgical site i.e. $2 \mathrm{ml}$ (total $4 \mathrm{ml}$ ), by the surgeon. In Group P, at the end of surgery following hemostasis, $2 \mathrm{ml}$ isotonic solution (total $4 \mathrm{ml}$ ) was applied as submucosal infiltration to both surgical sites by the surgeon. Post operative pain was evaluated using Visual analogue scale (VAS) scores at 1, 2, 4, 6, 12 and 24 hours (h) following surgery. There was no difference in additional analgesic consumption between two groups. Results: Post operative pain intensity was significantly lower in group $T$ in comparison with group $P$ during the first 24 hours after surgery $(P<0.001)$. Conclusion: Submucosal infiltration of tramadol in septoplasty patients can decrease post operative pain, analgesic consumption, and the time to recovery without significant side effects.
\end{abstract}

Keywords: Septoplasty, Submucosal tramadol, Postoperative pain,Visual Analogue Scale, Opioid

\section{Introduction}

Postoperative pain has not only a pathophysiologic impact but also affects the quality of patients' lives [1]. After septoplasty operations patients mainly complain about facial pain and discomfort. It is due to various causes such as excision of the cartilage causing septal deviation, sutures or anterior nasal packing placed for stabilization and surrounding tissues damage $[2,3]$. These lead to subsequent release of biochemical agents such as prostaglandins and histamine. These agents can then stimulate pain receptors, which send the pain message to the central nervous system to generate the sensation of pain [1]. Tramadol is a centrally acting opioid which is effective for moderate-severe pain and is used for various acute and chronic pain scenarios [4,5] Its weak local anaesthetic effect on peripheral nerves due to the blockage of voltage dependent $\mathrm{Na}$ channels has been shown in various studies [6]. A randomized double blind study was conducted to evaluate the effect of submucosal tramadol on VAS scores after septoplasty operations and patient satisfaction.

\section{Materials and Methods}

A prospective comparative study was conducted at the Department of ENT, Kempegowda Institute of Medical sciences, Bangalore from October 2015 to November 2016. 100 consenting adults of both sexes aged 18- 60 years belonging to ASA I-III risk groups were included in the study. Exclusion criteria were: no history of previous nasal surgery, morbid obesity, seizure disorder, anticoagulants, hepatic, renal or gastric illness and history of anxiolytic or sedative drug use in the last month, allergy to nonsteroid anti-inflammatory drugs and a history of opioid addiction.
The patients were randomized to two groups. All the operations were performed by the same surgeon who was blinded to group of the patient. The patients were evaluated in the postoperative period by the same surgeon.

In Group $\mathrm{T}$, at the end of surgery following hemostasis, $2 \mathrm{mg} / \mathrm{kg}$ tramadol was applied as submucosal infiltration to both surgical sites i.e. $2 \mathrm{ml}$ (total $4 \mathrm{ml}$ ), by the surgeon. In Group P, at the end of surgery following hemostasis, $2 \mathrm{ml}$ isotonic solution (total $4 \mathrm{ml}$ ) was applied as submucosal infiltration to both surgical sites by the surgeon. Killian septoplasty was carried out in all patients included in the study, no surgical intervention was done to sinuses and/or conchae. Merosel nasal pack was placed at the end of surgery and these were taken out at the end of $48 \mathrm{~h}$. VAS scores were recorded at 1, 2, 4, 6, 12 and 24 hours post operatively. The patients were asked to rate their satisfaction according to Likert scale (1: Completely comfortable, 2: Very comfortable, 3: Slight discomfort, 4: Painful, 5: Very painful) at the end of $24 \mathrm{~h}$.

\section{Statistical analysis}

Data tabulation and analysis using tests such as unpaired $t$ test for the parametric data and Chi square test and Mann Whitney $\mathrm{U}$ test for non parametric data,along with other statistical tests were applied and used to draw appropriate conclusions and table recommendations merited. 


\section{International Journal of Science and Research (IJSR) \\ ISSN (Online): 2319-7064 \\ Index Copernicus Value (2015): 78.96 | Impact Factor (2015): 6.391}

\section{Results}

100 patients were enrolled in the study. The age of patients in the study ranged from 18-60 years, $p-0.405$. (55\%) female and $(45 \%)$ male met the inclusion criteria of which Male : Female ratio in group $\mathrm{T}$ and $\mathrm{P}$ are 2:3 and 1:1 ratio (p- 1.3) respectively. The two groups did not differ according to their age, sex, and duration of anesthesia and surgery. There were no differences in postoperative heart rate, blood pressure, side effects and additional analgesic consumption such as nausea, vomiting, gastric irritation.

In our current study group $\mathrm{T}$ had significantly less pain scores.VAS values were higher in Group $\mathrm{P}$ on the first and second postoperative hours (PO). In PO $1^{\text {st }} \mathrm{h}$ Group $\mathrm{T}$ and Group P has VAS $20 \pm 5.4$ and $25 \pm 6.5$ respectively , $\mathrm{p}=0.017$. In PO $2^{\text {nd }}$ hour the VAS score was $12.7 \pm 11.7$ in Group T vs. $17.7 \pm 10.4$ in Group P, p $=0.045$. Statically and clinically significant result was seen at the PO end of 24 h.

Patient satisfaction was higher and opioid consumption was lower in Group $\mathrm{T}$ compared to Group P. There was no difference in additional analgesic consumption between two groups.

Table 1: Demograhic Data

\begin{tabular}{|c|c|c|c|}
\hline & Group T $(\mathrm{n}=50)$ & Group P(n=50) & $\mathrm{p}$ \\
\hline Age ( mean \pm SD) & $35 \pm 10$ & $38 \pm 5$ & 0.412 \\
\hline Sex & & & \\
Male & 20 & 25 & \\
Female & 30 & 25 & \\
(M:F) & $2: 3$ & $1: 1$ & 1.3 \\
\hline Weight & $75 \pm 10.5$ & $73 \pm 12$ & 0.435 \\
\hline Height & $169 \pm 5.5$ & $163 \pm 6$ & 0.617 \\
\hline
\end{tabular}

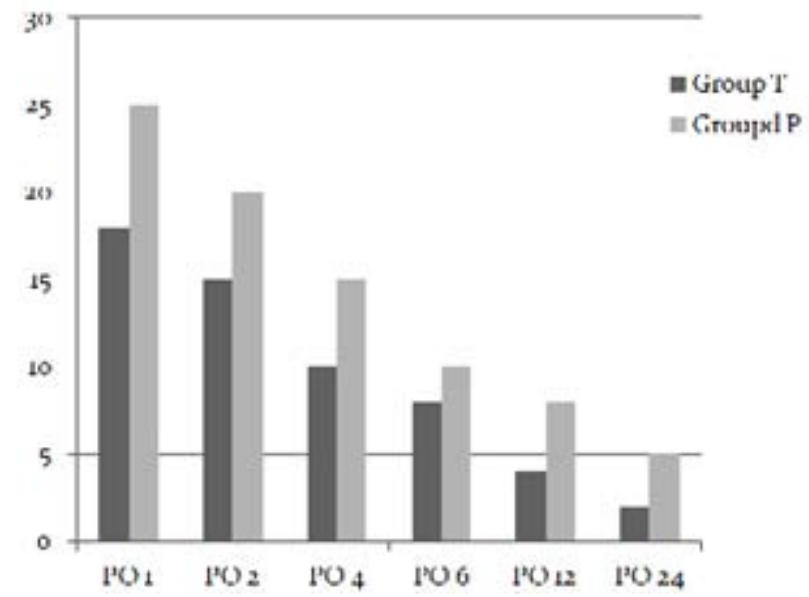

Graph 1: VAS Score

\section{Discussion}

Tramadol is a synthetic opioid which belongs to the aminocyclohexanol group and consists of two isomeres with different effect spectrums and has a local anaesthetic effect on peripheral nerves which was shown in clinical and laboratory studies $[5,7,8]$. It has been proposed that tramadol has a lidocaine-like mechanism of action which involves voltage dependent sodium channels causing axonal blockade. Jou et al suggested that tramadol affects sensory and motor nerve conduction by a similar mechanism to that of lidocaine, which acts on the voltage-dependent sodium channel leading to axonal blockage [9]. In contrast, Mert et al. proposed that tramadol might have a mechanism different from that of lidocaine for producing conduction block, the presence of a large $\mathrm{Ca}^{+2}$ concentration in the external medium increases tramadol's activity whereas decreasing lidocaine's activity[11].

Septoplasty operations, are characterized with mild to moderate facial pain, discomfort, minimal nasal bleed in the PO period[2,3]. In our study the effects of submucosal tramadol on PO analgesia using VAS score was accessed. Statistically and clinically significant result was noted in Group $T$ patients. This study has showed that tramadol decreases VAS scores and opioid consumption in the first $24 \mathrm{~h}$ when compared to Group P. Previous studies conducted showed similar results.

A study conducted by Honarmand A et al and Atef A et al. showed similar results. There was a significant decrease in pain score in post tonsillectomy patients receiving peritonsillar infilteration with tramado, p- 0.005. Similarly, it has been shown that $2 \mathrm{mg} / \mathrm{kg}$ tramadol used in peritonsillar infiltration prolongs the postoperative analgesia duration and reduces the need for additional analgesics and the incidence of side effects. The same results were observed in our study $[11,12]$.

Khajavi et al. evaluated the clinical efficacy of the subcutaneous infiltration of ketamine and tramadol at the incision site to reduce postoperative pain. PO pain intensity and analgesic comsumption was less as compared to control group , p- 0.001[13].

Altunkaya et al. reported that $2 \mathrm{mg} / \mathrm{kg}$ subcutaneous tramadol in minor surgery has a lidocaine-like effect. Following intramuscular injection tramadol is absorbed quickly and fully, reaches peak serum concentration in 45 min and sufficient serum concentration for minor pain treatment in approximately $7 \mathrm{~min}$. Altunkaya et al. concluded that tramadol may be a good choice for minor surgery using local anesthesia because of its sufficient local anesthetic and analgesic effects[14]

Demiraran et al. concluded that wound infiltration with tramadol ,2 $\mathrm{mg} / \mathrm{kg}$, in patients undergoing Cesarean section under general anesthesia provided better PO VAS score, $\mathrm{p}$ value- 0.0001. A similar study conducted again by Demiraran et al in post hernitotomy children had same results as above[15,16]. We observed a similar reduction in PO VAS score in the group receiving tramadol in our study.

\section{Conclusion}

NSAID and opioids, which are used for postoperative analgesia are known for their side effects like bleeding, gastrointestinal irritation, nausea and vomiting ' In our current study, submucosal infilteration of tramadol did not increase the incidence of side effects. in contrast, it decreased the usage of systemic opioid. Thus, submucosal

\section{Volume 6 Issue 1, January 2017




\section{International Journal of Science and Research (IJSR) \\ ISSN (Online): 2319-7064 \\ Index Copernicus Value (2015): 78.96 | Impact Factor (2015): 6.391}

tramadol provides efficient analgesia, reduces intravenous opioid consumption and increases patient satisfaction.

\section{References}

[1] Morrison RS, Magaziner J, McLaughlin MA, Orosz G, Silberzweig SB, Koval KJ, Siu AL. The impact of postoperative pain on outcomes following hip fracture. Pain. 2003 Jun 30;103(3):303-11.

[2] Bloom JD, Kaplan SE, Bleier BS, Goldstein SA. Septoplasty complications: avoidance and management. Otolaryngologic clinics of North America. 2009 Jun 30;42(3):463-81.

[3] Weber R, Keerl R, Hochapfel F, Draf W, Toffel PH. Packing in endonasal surgery. American journal of otolaryngology. 2001 Oct 31;22(5):306-20.

[4] Hennies HH, Friderichs E, Schneider J. Receptor binding, analgesic and antitussive potency of tramadol and other selected opioids. Arzneimittel-forschung. $1988 \mathrm{Jul} ; 38(7): 877-80$.

[5] Reimann W, Schneider F. Induction of 5hydroxytryptamine release by tramadol, fenfluramine and reserpine. European journal of pharmacology. 1998 May 22;349(2):199-203.

[6] Mert T, Gunes Y, Guven M, Gunay I, Ozcengiz D. Comparison of nerve conduction blocks by an opioid and a local anesthetic. European journal of pharmacology. 2002 Mar 29;439(1):77-81.

[7] Mert T, Gunes Y, Gunay I. Local analgesic efficacy of tramadol following intraplantar injection. European journal of pharmacology. 2007 Mar 8;558(1):68-72.

[8] Raffa RB, Friderichs E, Reimann W, Shank RP, Codd EE, Vaught JL. Opioid and nonopioid components independently contribute to the mechanism of action of tramadol, an'atypical'opioid analgesic. Journal of Pharmacology and Experimental Therapeutics. 1992 Jan 1;260(1):275-85

[9] Jou IM, Chu KS, Chen HH, Chang PJ, Tsai YC. The effects of intrathecal tramadol on spinal somatosensoryevoked potentials and motor-evoked responses in rats. Anesthesia \& Analgesia. 2003 Mar 1;96(3):783-8.

[10] Mert T, Gunes Y, Guven M, Gunay I, Ozcengiz D. Comparison of nerve conduction blocks by an opioid and a local anesthetic. European journal of pharmacology. 2002 Mar 29;439(1):77-81.

[11] Atef A, Fawaz AA. Peritonsillar infiltration with tramadol improves pediatric tonsillectomy pain. European Archives of Oto-Rhino-Laryngology. 2008 May 1;265(5):571-4.

[12] Honarmand A, Safavi M, Naghibi K, Attari M, Soltani M, Amoushahi M, Sadeghipanah F. Preemptive peritonsillar infiltration with bupivacaine in combination with tramadol improves pediatric posttonsillectomy pain better than using bupivacaine or tramadol alone: A randomized, placebo-controlled, double blind clinical trial. Advanced biomedical research. 2015;4.

[13] Khajavi MR, Navardi M, Moharari RS, Pourfakhr P, Khalili N, Etezadi F, Imani F. Combined KetamineTramadol Subcutaneous Wound Infiltration for Multimodal Postoperative Analgesia: A DoubleBlinded, Randomized Controlled Trial after Renal
Surgery. Anesthesiology and Pain Medicine. 2016 Oct;6(5).

[14] Altunkaya H, Ozer Y, Kargi E, Ozkocak I, Hosnuter M, Demirel CB, Babuccu O. The postoperative analgesic effect of tramadol when used as subcutaneous local anesthetic. Anesthesia \& Analgesia. 2004 Nov 1;99(5):1461-4.

[15] Demiraran Y, Albayrak M, Yorulmaz IS, Ozdemir I. Tramadol and levobupivacaine wound infiltration at cesarean delivery for postoperative analgesia. Journal of anesthesia. 2013 Apr 1;27(2):175-9.

[16]Demiraran Y, Ilce Z, Kocaman B, Bozkurt P. Does tramadol wound infiltration offer an advantage over bupivacaine for postoperative analgesia in children following herniotomy. Pediatric Anesthesia. 2006 Oct $1 ; 16(10): 1047-50$. 